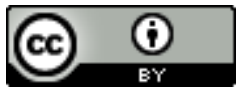

Esta obra está sob o direito de Licença Creative Commons Atribuição 4.0 Internacional.

\title{
LER, CONHECER, APRENDER E DESENVOLVER: PRODUZIR CONHECIMENTOS ATRAVÉS DAS PALAVRAS
}

\section{Elisângela Oliveira Tavares ${ }^{1}$}

Maria das Graças Sandes de Araújo ${ }^{2}$

Sônia Maria da Silva Lima ${ }^{3}$

Luciano Canuto Jacinto ${ }^{4}$

Maria Edleuza da Paz ${ }^{5}$

Jayra dos Santos Costa Rocha ${ }^{6}$

\section{RESUMO}

A escola tem um papel fundamental na construção do conhecimento, adotando a prática da Leitura, a integração do ensino-aprendizagem para uma atividade reflexiva para avançar o desenvolvimento da escrita e da Leitura. O objetivo desse estudo é reconhecer os significados e uso das palavras em diferentes contextos, através da pesquisa bibliográfica. Com tudo, mostrando a importância para incentiva a leitura e escrita para formar verdadeiros leitores e escritores, por meio do ler e escrever, conhecendo as palavras.

Palavras-chaves: Ler; Escrever; aprender; Leitura.

\footnotetext{
1 ely_tavares@hotmail.com

2 gsandes.sandes@gmail.com

3 sonialima95@gmail.com

4 lucianocanutojacinto11@gmail.com

5 mariaedileuza.leu@gmail.com

6 jayra_costa@hotmail.com
} 


\section{INTRODUÇÃO}

A compreensão é a proficiência da Leitura evoluem ao longo do desenvolvimento da Criança e relacionar-se com a compreensão de outras informações que a criança obtém através da comunicação além da escrita. A compreensão da informação depende do desenvolvimento das capacidades para selecionar e organizar informações. A leitura põe em jogo Duas atividades, a identificação dos signos que compõem a

\section{METODOLOGIA}

Trata-se de uma revisão de literatura tradicional, não sistemática, descritiva, de natureza qualitativa e bibliográfica, já que a

\section{REFERENCIAL TEÓRICO}

\section{Ler, conhecer, aprender e desenvolver}

A educação como instrumento de reprodução para a sociedade, aquela que tem por finalidadeprincipal a adaptação do sujeito a sociedade. A educação como instrumento de transformação da sociedade refere-se a educação crítica, aquela que tem como finalidade principal a instrumentalização dos sujeitos para que esses tenham uma prática social crítica e transformadora. Pois os sujeitos precisam se apropriar de conhecimentos, ideias vírgulas atitudes vírgulas valores e etc. de forma crítica e reflexiva para que tenham linguagem escrita e a compreensão do Significado da linguagem escrita, Pois é a compreensão de um texto que depende sempre da descodificação da escrita. Não basta aprender a ler, é necessário aprender como que se lê é necessário interpretar os conteúdos e atribuir-lhes significado para que a leitura seja interpretada não como um ato mecânico de juntar as letras e formar palavras, mais um verdadeiro diálogo do leitor com o autor (ARAUJO, 2017).

análise se realizou em diversas fontes de pesquisas como conteúdo de livros, artigos científicos, sites, dissertações, teses e bibliográficas virtuais.

condições de atuar nessa sociedade visando a sua transformação (CRAVO, 2018).

A leitura é importante na melhoria do processo de ensino-aprendizagem, contribuindo para o desenvolvimento dos leitores. O conhecimento é a compreensão da transformação do mundo, é uma necessidade para ação e ainda, como elemento de libertação ( luckesi, 1985). Segundo o autor, nos remete A reflexão sobre nosso mundo cultural. O mundo humano é um mundo constituído pela cultura, pelo sujeito humanos em sua relação entre si e deles com o ambiente em que vivem. Vivemos num mundo em 
constante atividade. Observamos, sentimos e agimos, mas principalmente pensamos.

Todos os nossos atos são acompanhados de pensamento, de reflexões sobre o observado, então, necessitamos, além de viver no mundo, pensá-lo, compreendê-lo, Isto é, conhecê-lo. Essa ação de diferenciada de pensar o mundo e suas coisas e o movimento humano de dar significado a tudo, de compreender a vírgula da forma mais aprofundada possível, com os conhecimentos relacionados, das expectativas estratégias com a compreensão do texto através do ato da Leitura. A literatura determina as ideias principais do texto, gerando questões sobre o conteúdos, monitorando a sua compreensão e informação (SANTOS, 2017).

A capacidade de separar os aspectos dos detalhes é um dos fatores que diferenciam os leitores na sua eficácia e esta muito associado a compreensão do texto, aquilo que o leitor considera mais importante o Ato da leitura e por isso é mas memorizado, com isso os leitores são mais eficazes tem maior capacidade de selecionar os elementos importantes do texto. Os bons leitores procuram avaliar os textos e usam seus conhecimentos da estrutura do texto para identificar e organizar informação (POLLO, 2015).

Durante a leitura, estes leitores envolvem-se ativamente um bom conhecimento, os bons leitores tem consciência de até que ponto compreendem as suas ideias importantes do texto com objetivos de leitura. A identificação das ideias principais é também influenciada por elementos próprios do texto, como o tipo de vocabulário usado pelo autor (CRAVO, 2018).

Os alunos são agentes ativos da sua aprendizagem, são capazes de construir significado adquiridos na escola. Os professores, por seu lado, são agentes mediadores desta aprendizagem, mais do que os transmissores de saber, eles podem apoiar o aluno, tanto na construção dos significados quanto no desenvolvimento de estratégias que facilitem a leitura e a sua compreensão. O objetivo da leitura é a construção do significado, independentemente da idade e da capacidade do leitor (ARAUJO, 2017).

Doll (1975)" tal como um bom leitor tem em mente uma ideia acerca de forma como construir o significado do texto, o professor também tem alguma ideia acerca de nossas relações com o mundo e com as coisas" temos como pressupostos básicos que o conhecimento só nasce da prática com o mundo, enfrentando os seus desafios e as resistências e que o conhecimento só tem seu sentido pleno na relação com a realidade.

Assim, o conhecimento torna-se compreensão teórica do mundo e das coisas, 
ou seja a uma elaboração no pensamento em busca de significado. Contudo, a também uma ação prática, Pois é definição elaborada no pensamento conduz a ação, ao modo de agir sobre o mundo compreendido, ou seja significado:

O conhecimento é uma capacidade disponível em nós, seres humanos, para que processamos de forma mais adequada a nossa vida, com menos risco. O conhecimento tem o poder de transformar a capacidade da realidade em caminhos iluminados de tal forma que nos permite agir com a certeza, segurança e previsão (Luckesi,1985, p.51).

Nesse sentido, buscamos conhecer, significar e compreender todas as situações vividas. Todo conhecimento tem como objetivo a convivência dos sujeitos com o mundo e as coisas que o cercam, uma convivência compreendida, significado, agir sobre o mundo para transformá-lo exige a sua compreensão, interpretação. Então, a busca do conhecimento, de compreensão e significação para o mundo e as coisas é uma atitude essencialmente humana (CRAVO, 2018).

O processo de elaboração de conhecimento sobre o mundo não é um processo individual. Os significados produzidos para a sua compreensão foram e são produzidos durante toda a história da humanidade pelo conjunto dos sujeitos sociais. Isso significa que o conhecimento é histórico e social. Histórico, por que cada conhecimento novo é um aprofundamento de conhecimentos anteriores e social, porque nenhum sujeito constrói um conhecimento totalmente novo (SANTOS, 2017).

Todo conhecimento apoia-se em conhecimentos anteriores, produzidos por outros sujeitos. Além de diferenciar os sujeitos pela possibilidade de compreender o mundo por meio do pensamento, o conhecimento fundamenta a ação sobre o mundo. A ação significa conhecer, compreender, seus múltiplos aspectos (ARAUJO, 2017).

O conhecimento e ação humana sobre o mundo e as coisas é a luz do caminho a ser percorrido. Agir e sentir pensando e compreendendo é uma característica humana, isto é, não conseguimos viver sem compreender o mundo que nos rodeia, a busca pelo conhecimento, pelos instrumentos necessários para dar direção As Nossas ações (POLLO, 2015).

A leitura evolui ao longo do desenvolvimento da criança e relacionamse com a compreensão de outras informações que a criança obtém através de outros sistemas de comunicação além da escrita. A compreensão da informação linguística depende do desenvolvimento das capacidades cognitivas para selecionar, 
processar e organizar informações. O professor pode contribuir para tornar a criança um leitor apto, capaz de desenvolver os conhecimentos com a sua criatividade e desempenho (ARAUJO, 2017).

Compreender a linguagem implica descodificar uma mensagem de um modo ativo. Não se trata de integrar mecanicamente a mensagem do autor, acrescentando-lhes qualquer coisa. Trata-se pelo contrário, de um processo em que é feita uma associação entre o texto percepcionado e os conhecimentos que o sujeito traz a leitura (CRAVO, 2018).

O leitor é um agente ativo, capaz de construir e reconstruir o significado do texto a medida que o lê, através da Integração das novas informações. Como apoiar o aluno nesse trabalho. O professor pode alterar as suas ações e objetivos. O texto sendo a unidade básica da leitura é um instrumento que cada professor deve utilizá-lo sala de aula, trazendo o contexto educacional os diversos gêneros textuais, os parâmetros curriculares nacionais afirmam que:

Cabe à escola viabilizar o acesso do aluno do universo dos textos que circulam socialmente, ensinar e produzilos e a interpretá-los. Inclui os textos das diferentes disciplinas, qual os quais $\mathrm{o}$ aluno se defronta sistematicamente no cotidiano escolar e, mesmo assim, não consegue manejar, pois não há um trabalho planejado com essa finalidade. (PCN 1997, p.30).

Tão importante quanto conhecer o funcionamento do sistema da escrita é poder trabalhar as práticas do letramento.

Enquanto a alfabetização se ocupa da aquisição da escrita por um indivíduo, o letramento focaliza os aspectos sóciohistóricos da sociedade (Tfouni,1995, p.20).

O processo de alfabetização incorpora a experiência do letramento em função de como ensino da língua escrita, Paulo Freire (2001), a leitura do o mundo precede a leitura da palavra, daí que a posterior leitura desta não possa prescindir da continuidade da Leitura, daquele, linguagem e realidade se prendem dinamicamente.

Ler Implica também uma reflexão sobre a prática, os seus fins e os seus métodos. A leitura é de fundamental importância para o estudo, para a construção e reconstrução do conhecimento dos objetos da realidade.

Ler como um ato de estudar, não é simples passatempo, mais uma tarefa séria, em que os leitores procuram clarificar as dimensões ópticas de seu estado (Freire,1992, p.87). 
O leitor não deve assumir uma atitude crítica e nem passiva, memorizando e absorvendo mecanicamente o conteúdo do texto. Além disso, a atitude crítica e passiva no ato de ler, leva ao leitor um desafio em sua realidade social. Morin (1999), uma teoria não é o conhecimento, que sinaliza para as necessidades da teoria, ou seja, interpretadas, reconstruídas e compreendidas.

Significa que cada um precisa, com base nos seus conhecimentos prévios, fazer relações, articular os conhecimentos construídos ao longo da história, compreendendo, traduzindo e interpretando como o sujeito que aprendem significativamente (POLLO, 2015).

Ferreiro (1985), aprender a ler e a escrever, lendo e escrevendo ponto na aprendizagem da leitura e escrita, Primeiro é preciso aprender a codificar e decodificar para depois aprender a produzir compreender. Ao Trabalhar leitura, estamos mostrando como é o mundo em que estão. Pois traz informações valiosas sobre a língua escrita.

Mesmo antes de poder ler por conta própria, quando a criança entra em contato com texto escrito, ela pensa sobre a língua escrita, conheço seu código e o seu funcionamento, ela escuta a leitura, entra em contato com sua função. Obtendo informações quando observa o adulto, lendo a sua volta. Observando seus pais, a criança tomar a os textos como algo de valor (SANTOS, 2017).

A criança estará em formação de um bom leitor no futuro, ouvindo um adulto lendo para ela desde cedo, mais informações ela terá acerca da língua escrita e da Leitura. Quando lemos para uma criança, estamos afetivamente se aproximando dela, a leitura contribui uma aproximação compartilhada, que reforça os afetos entre família (POLLO, 2015).

Para ser um boleto é necessário maior contato possível com diferentes textos, quanto a criança conhecer, mais habilidade terá para ler. Será um bom leitor, aquele que compreender o conteúdo de um texto, opinando diante dele. Vigostsky (1979), a capacitação humana para a linguagem, a criança providenciar instrumentos auxiliares na sua solução, a planejarem a solução para um problema antes da execução e a controlarem seu próprio comportamento.

Signos e palavras constituem para as crianças, primeiro e acima de tudo, um meio de contato social com outras pessoas. As funções cognitivas e comunicativas da linguagem tornam-se então a base de uma forma nova e superior de atividades nas crianças distinguindo-as dos animais (Vigostsky,1984, p.42).

A criança utiliza a fala como meio exterior, com os adultos e outras crianças. 
Pois ela começa a usar a fala como comunicação, é como uma criança falasse com ela mesmo com o domínio da linguagem que promove mudanças nas crianças, pois possibilita novas formas de comunicação no modo de agir, pensar e interpretar o mundo.

A leitura é o meio mais eficiente de enriquecimento e desenvolvimento da personalidade, é um passaporte para a vida e para a sociedade (Ávila,1971, p.35).

Após adquirir o domínio da fala a criança começa a interagir com a leitura. Ela trabalha com a criatividade, propiciando maior aprendizagem.

Ensina se a criança desenhar letras, e construir palavras com elas, mais não se ensina a linguagem escrita. Enfatiza de tal forma a mecânica de ler o que está escrito que se acaba obscurecendo a linguagem escrita como tal (Vygostsky,1991, p.33).

Estimulando o hábito de ler, desenvolve o prazer da Leitura. Ler o mundo e também lê o espaço, construção social e histórica da ação humana. Assim ler o mundo é estudar a sociedade. Milton Santos (1996), é na contemporaneidade, especialmente, estudar as relações sociais e na sociedade.
$\mathrm{O}$ ato de aprender a ler e escrever deve começar a partir de uma compreensão muito abrangente do ato de ler o mundo, coisa que os seres humanos fazem antes de ler a palavra. Até mesmo historicamente, os seres humanos primeiro mudaram o mundo, depois revelaram o mundo é a seguir escreverem as palavras. Esses são momentos da história. Os seres humanos não começaram por nomear (Freire,1990, p.32).

Com base em Freire em sua Concepção do ato de ler, compreende que a linguagem e realidade se constroem mutualmente, a percepção das relações entre o texto e o contexto, onde a leitura da palavra com a leitura do mundo (Freire,1986).

Porém, ler e interpretar e captar a realidade, é conhecer o significado pela interpretação (Gutierrez,1978).

A escrita é um produto cultural por Excelência. Historicamente, pode-se dizer que a cultura escrita é uma invenção recente da humanidade. Segundo Walter Ong, estudioso da oralidade da escrita. A sociedade humana primeiramente se formou com ajuda do discurso oral, tornando-se letrado muito mais tarde em sua história. (Walter Ong,1998, p.10).

O predomínio da linguagem oral sobre a linguagem escrita, que dá sustentação a toda a comunicação verbal. Adquirir a linguagem escrita implica poder 
fazer uso de novas ações de pensamento, porém, é importante ressaltar que a escrita não é a única responsável por essas formas de pensar, Oliveira (1995).

O mundo letrado por ações coletivas, propiciam transformações diferenciadas. Sendo assim a apropriação da linguagem escrita, propícias mudanças de qualidade e cognitivas do seu uso. Assim, todo o ato de observação que nos permite reconhecer um significado pode ser considerado como um ato de leitura.

A escrita domina um amplo conjunto de habilidades, o ato de escrever difere do ler, porque exige do escritor o domínio que lhe permite transformar uma ideia em desenho Olson (1997).

Essa afirmação, faz-se necessária a compreensão culturalmente construída de que a representação de objeto, tanto por meio de traços que nos permite reconhecêlo, quanto por meio dos registros do nome do objeto. Escrever as letras que representam sons, os quais identificam o nome do objeto representado.

Nessa concepção, aprender a ler e a escrever está diretamente relacionado ao próprio desenvolvimento do aprender a pensar (Vygotsky,1989).

A escola é um espaço educativo na aprendizagem de seus alunos para torná-los um bom leitor de vários gêneros textuais.
Uma outra atitude é problematizar o nosso olhar sobre o mundo, reaproximando-os Santos (1996), apostando no movimento de Constituição de um novo senso comum, ético porque solidário, estético porque recantado, político porque participativo Santos (1995). O olhar pode ser muito, mas que ver, compreendendo que, o olhar nada mais é que o resultado de que lê o mundo através da Cultura.

A língua escrita é um veículo de comunicação com valores e conhecimentos sobre o mundo. Os benefícios da leitura são evidentes para a maioria dos leitores para comunicação e aprendizagem. A escola é um grande Nice a dor a leitura para as crianças, garantindo uma atividade com forte significado. A leitura não pode ser representada como uma atividade mecânica, mais como uma atividade construtiva para o aluno, como algo a ser compreendido de modo tão completo que assegure que o ato de ler é um verdadeiro ato da aprendizagem (ARAUJO, 2017).

A educação no Brasil está em uma situação de pleno desenvolvimento, isto nos leva a reconhecer que temos muitas escolhas, venha à responsabilidade de fazer uma prática criativa no sentido de produzir conhecimentos para uma pratica tão rica e diversa área (CRAVO, 2018) 


\section{CONCLUSÃO}

Concluindo, construir práticas na educação, além de contribuir na construção do conhecimento, formando jovens críticos e desenvolvendo, processos inovadores para uma leitura reflexiva de cada prática. Só assim será possível desenvolver dinâmicas e o gosto pela leitura, possibilitando-lhe e estimulando-os a prática dos valores e a participação cidadã na vida dos jovens.

\section{REFERÊNCIAS}

Luckesi,c.c. uma proposta metodológica. São Paulo: Cortez, 1985.

Parâmetros curriculares nacionais, ensino fundamental. Língua portuguesa.

Brasília:MEC/SEF 1997.

Vygotsky, Lev. A formação da mente. $6^{\circ}$ ed. São Paulo: Martins Fontes, 1984.

Santos Milton. O pensamento linico. Rio de Janeiro: Record, 1996.

Freire,P. Educação na cidade. São Paulo: Cortez, 1990.

Freire,P. A importância do ato de ler. São Paulo: Cortez, 1986.

Ong, W. Oralidade e cultura escrita. São Paulo: Ática, 1998.

Olson, D. O mundo no papel. São Paulo: 1997.

Tfouni, Leda verdiani, escrita, alfabetização e letramento. São Paulo: Cortez, 1995.
A escola tem muito a ensinar a vírgula quando se propõe a preparar seu aluno para o desenvolvimento da Leitura, o ensino da Leitura pode contribuir para a maior conscientização do aluno envolvido na construção do texto. $\mathrm{O}$ ato de ler pode constituir a formação na construção do conhecimento que amplia a sua visão do mundo, a partir do ato da Leitura contribuindo e educando para seu crescimento intelectual.

Freire, P. Pedagogia da Esperança: um reencontro com a pedagogia do oprimido: Rio de Janeiro:paz e Terra. 1992.

Freire, p. Educação e atualidade brasileira. São Paulo; 2001 Morin,Edgar. O método 3: O conhecimento do conhecimento ponto final Porto Alegre: Sulina, 1999.

Ferreiro, Emília;teberosk, Ana ponto final a psicogênese da língua escrita. Porto Alegre: Artes médicas, 1985.

Vygotsky, L.S. a formação social da mente. São Paulo: Martins Fontes, 1991.

Vygostsky, L.S. pensamento e linguagem. São Paulo: Martins Fontes, 1979.

Oliveira,M.K. letramento, cultura e modalidade de pensamento. São Paulo: mercado de letra, 1995.

Vygotsky,L.S. pensamento e linguagem. São Paulo: Martins Fontes, 1989.

D'Avila, A. O professor. São Paulo 2 pontos 1971. 
Dolle, J.M. para compreender Jean Piaget. Rio de Janeiro: Zahar, 1975.

ARAUJO, L. C. De. Ler, Escrever E Brincar Na Educação Infantil: Uma Dicotomia Mal Colocada. Revista Contemporânea de Educação, 2017. v. 12 , n. 24, p. 344.

POLLO, T. C.; TREIMAN, R.; KESSLER, B. Uma revisão crítica de três perspectivas sobre o desenvolvimento da escrita.

Estudos de Psicologia (Campinas), 2015. v. 32, n. 3, p. 449-459.

SANTOS, M. J. DOS; BARRERA, S. D. Impacto do treino em habilidades de CRAVO, F. A. M.; ALMEIDA-VERDU, A. C. M. Evaluation of school performance after exposure to a computerized reading and writing program. Revista Psicologia consciência fonológica na escrita de préescolares. Psicologia Escolar e

Educacional, 2017. v. 21, n. 1, p. 93-102. da Educação, 2018. v. 1, n. 47, p. 1-10. 